\title{
Inter-twin Relationships and Mental Health
}

\author{
Hanna Ebeling', Tuulikki Porkka', Varpu Penninkilampi-Kerola², Eija Berg³, Sari Järvi,, and Irma Moilanen' \\ 'Clinic of Child Psychiatry, Department of Paediatrics, University and University Hospital of Oulu, Oulu, Finland \\ ${ }^{2}$ Clinic of Child Psychiatry, Department of Paediatrics, University of Oulu, Oulu, Finland, and Department of Public Health, \\ University of Helsinki, Finland \\ ${ }^{3}$ Department of Radiology, University Hospital of Tampere, Tampere, Finland \\ ${ }^{4}$ Clinic of Child Psychiatry, Central Hospital of Seinäjoki, Seinäjoki, Finland
}

\begin{abstract}
W: evaluated dominance-submissiveness between cotwins and its relationship to mental health in a cohort study of 419 twins followed from pregnancy to 22-30 years of age. Dominance-submissiveness between co-twins was assessed from three separate perspectives: physical dominance, psychological dominance, and verbal dominance. Depressive, nervous, and psychosomatic symptoms were analyzed in different twin groups. In the physical domain, males were more commonly dominant than females at school age and in adulthood. Before and at school age, girls were more dominant than boys in the psychological and verbal domains, as well as in total dominance. These differences disappeared in adulthood, and $81 \%$ of adult twins felt themselves equal to their co-twin in total dominance. Submissiveness in the psychological domain seemed to be associated with increased depressiveness, nervous complaints and psychosomatic symptoms in males of male-female twin pairs. Verbally submissive males in same-sex twin pairs had more depression and psychosomatic symptoms. Among females of same-sex twin pairs, submissiveness in the psychological domain was most clearly associated with depressive symptoms, whereas psychological or verbal dominance-submissiveness among females from male-female twin pairs was not associated with symptoms. Psychologically dominant males and females of same-sex twin pairs expressed greater nervousness than did their co-twins. We conclude that being submissive, especially in the psychological domain, to a female twin partner seems to be stressful, whereas it is easier, especially for females, to be submissive to a male twin partner.
\end{abstract}

Twins provide a sibling relationship that is different from the sibling relationship of singleton children. Living and growing together with a co-twin, who is constantly there with more or less the same developmental needs and tasks, may be a fruitful developmental environment, but it may also create a developmentally challenging situation. The important thing is how the closest persons around the twins, such as the parents and other family members, and the twins themselves adapt to the situation. One issue is the ability of twins to deal with the continual comparisons made between them and to shift from possible competition to cooperation or other constructive and unbiased forms of interaction. Still, relatively little is known of the different features of twin relationships and their consequences (Rutter \& Redshaw, 1991). Studies of singletons suggest that the quality of sibling relationships is stable from middle childhood into adolescence (Brody et al., 1994).
Understanding the variation in the quality of twin relationships is, therefore, important.

Many studies of sibling interactions among twins indicate that twins are asymmetrical in their relationship and enact complementary roles relative to one another (Ainslie, 1985; Robin et al., 1988; Schave \& Ciriello, 1983). This asymmetry is also implicit in the dominance-submissiveness between twins, as previous studies have shown (Lytton, 1980; Moilanen, 1987a). Qualitative studies have suggested that dominance also seems to have various manifestations among twins (Ainslie, 1985). In childhood and early adolescence, the split roles of dominance and submissiveness in a twin pair may serve an important function. By conquering different areas of expertise or domains of selfhood, twin siblings can avoid conflict and enhance mutual cooperation. Split roles can also help twins to develop their sense of self as separate from the co-twin by having certain distinguishing characteristics. Problems may occur if the process of individualization is not successful and one or both twins continue to identify themselves by their twinship.

Twinship offers opportunities to develop and practice dominance and submissiveness within a special developmental context involving a same-aged sibling. It seems that imbalance in dominance-submissiveness may constitute a developmental stress or, on the other hand, reflect existing health-related and social problems. Perinatal complications appear to be predictive of submissiveness (Moilanen, 1987a; Tienari, 1966). The more submissive and dependent member of a twin pair has been reported to have a higher incidence of psychiatric problems; for example, schizophrenia (Kringlen, 1967; Tienari, 1966, 1963) or anorexia nervosa (Bruch, 1969). In adolescence, the submissive twin seems to suffer more commonly from psychosomatic symptoms, whereas the dominant one suffers more commonly from nervous symptoms (Moilanen, 1991).

Associations between different aspects of twin dominance and the wellbeing of twins in different twin pairs has not been studied previously. The present study focuses on the different aspects of twins' dominance-submissiveness

Address for correspondence: Hanna Ebeling, MD, Ph.D, Clinic of Child Psychiatry, Department of Paediatrics University and University Hospital of Oulu, PO Box 26, Fin-OYS 90029, Oulu Finland. Email: hanna.ebeling@oulu.fi 
and its implications for their mental health in young adulthood, at 22-30 years of age.

\section{Material and Methods}

The original study sample comprised all 335 twin deliveries in Oulu University Hospital during the years 1965-1973 (Jouppila et al., 1975; Kauppila et al., 1975; Koivisto et al., 1975). Following perinatal and neonatal (0-28 days) mortality, a total of 603 (90\%) twins comprising 289 twin pairs and 25 single twins whose co-twin had died were alive at the end of the neonatal period. Pregnancy, delivery, and neonatal data were gathered from the hospital records.

In 1975-1976, a follow-up study was carried out in this twin cohort $(n=572)$, then aged $2-10$ years. Records were collected from health care centers for 272 twin pairs and 20 "single" twins. Parents filled in questionnaires about 260 twin pairs and 17 single twins. Information about 93 samesex (SS) male twin-pairs, 77 SS female twin pairs, and 105 opposite-sex (OS) twin pairs was collected at this point. The information included data about development, health, temperament, and twin relationship. Every third twin pair and all twins who had lost their co-twin during the perinatal or neonatal period (and thus had an elevated risk for developmental disorders) were invited to the outpatient clinic of the pediatric hospital for examinations. Pediatric, developmental, and neurological examinations were carried out, including EEG $(n=168)$. Additional psychological assessments (WISC, Bender, Goodenough) were made of all those who were at least 5 years old $(n=120)$ (Moilanen, 1979).

A second follow-up was conducted in 1985 , when the twins were 12-20 years old, by using questionnaires completed by the parents and the twins themselves, and by inviting the twins who had undergone the entire examination package in 1975-1976, to the outpatient clinic. Data on development, academic achievement, health and lifestyle, psychosomatic symptoms, inter-twin relationships, and parent-twin relationships were elicited, and additionally, the twins completed the Children's Depression Inventory (CDI; Kovacs, 1980). The dominance-submissiveness of the co-twins was assessed separately in three domains of life: physical and psychological dominance-submissiveness and the role of a spokesperson (Moilanen, 1987a,1987b). At the outpatient clinic, a pediatric somatic examination was performed, inter-twin and parent-twin relationships were inquired in line with, for example, Schave and Ciriello (1983), and a psychiatric Present State Examination (PSE; Wing et al., 1977) was made by another child psychiatrist blinded to the previous data and the contents of the earlier interviews (conducted by IM). Questionnaires were sent to the probands who had responded to the first follow-up inquiry. Questionnaire data were received from 497 twins $(82.4 \%$ of the original 603 twins). In addition interviews were conducted with 84 twins (Moilanen, 1987a, 1987b; Moilanen, 1988a, 1988b; Moilanen, 1991; Moilanen \& Pennanen, 1997).

A third follow-up was carried out in 1995, when the twins were 22-30 years old. The twins completed questionnaires about academic achievement, health and lifestyle, and life circumstances, such as employment and their own family and children. Inter-twin relationships were assessed as well. Dominance-submissiveness between twins and in the twin relationship was again assessed separately in three domains of life: physical and psychological dominance-submissiveness and the role of a spokesperson, here referred to as verbal dominance (Moilanen, 1987a, 1987b; Moilanen \& Ebeling, 1998). The reply alternatives to the questions were 1) I was always dominant, 2) I was often dominant, 3) We were equal, 4) My twin was often dominant, and 5) My twin was always dominant. For the present data analyses, the alternatives 1) and 2) were combined into "dominant", while 3) was "equal" and the alternatives 4) and 5) "submissive". A sum variable for "total dominance-submissiveness" was calculated by adding up the three features of dominance on a scale of 3 to 15 points, where 3-7 corresponded to dominant, 8-10 to equal, and 11-15 to submissive.

Depressive scores were measured by CDI, in which the questions were modified for age. Twenty-six items on a scale from 0 to 2 were used. The item about suicidal tendencies had been excluded from the previous inquiries for ethical reasons and was excluded here as well. The mean values of the total scores were calculated, and additionally, three subscores were formed based on a factor analysis performed on an epidemiological study in Finland (Moilanen, 1990). The factors were "low self-confidence" (items: I hate myself, nobody loves me, I look ugly, I am bad, I do everything wrong, I do everything very badly), "anhedony" (items: nothing is fun, things bother me, I never have fun at my studies or at work), and "sadness" (items: I am sad all the time, I feel like crying, I feel lonely).

Items assessing nervous complaints and psychosomatic symptoms were adapted from previous Finnish studies of juvenile health habits (Rimpela et al., 1983). Twins selfreported the frequency of occurrence of their symptoms, the frequencies of which were evaluated by assigning four ordered values to occurrences "never or less than monthly" (0), "monthly" (1), "weekly" (2), and "daily" (3), respectively. Factor analysis had yielded two distinct factors (Moilanen, 1987b). First, nervous complaints included nervousness, irritability, and loss of energy, and secondly, somatic complaints included headache and abdominal pain, and two sum variables were formed by adding together the scores of these separate groups of symptoms. At this follow-up, 419 twins whose co-twin was alive (72.5\% of the original 578 ) responded. Of the probands, 123 were males of SS twin pairs, 78 were males of OS pairs, 131 were females of SS twin pairs, and 87 females of OS twin pairs.

The Pearson Chi-Square test or Analysis of Variance, and Mann-Whitney U-test or Kruskal-Wallis test were performed. In post hoc analysis Bonferroni's test significance levels were used. If the data was missing in one third or less of the sum-variable items, the missing data was replaced by modes $(=0)$, otherwise the case was excluded from the analyses. The analyses were performed using SPSS versions 9.0 and 10.0. We wanted to test whether submissiveness was associated with psychiatric symptoms, and if twins from SS and OS pairs reported symptoms differently in connection with dominance-submissiveness.

\section{Results}

The present paper is based on an analysis of the questionnaires administered when the twins were 22-30 years old. 
Table 1 shows the proportions of dominance-submissiveness at different ages, retrospectively reported by the twins at this age. An intermediate dominance-submissiveness relationship was most common, especially in the psychological domain. In the physical domain, males were more commonly dominant than females at and after school age. In contrast, before and at school age, girls were more dominant than boys in the psychological domain and verbally as the pair's spokesperson as well as in total dominance. However, these differences levelled off in adulthood. Submissiveness in one domain was often compensated for by dominance in another, and equality between co-twins in their dominance-submissiveness increased with age. After school age, $81 \%$ of twins considered themselves equal to their co-twin.

There was no difference in depression or its subscores or in nervousness between the genders, but females had more psychosomatic symptoms (mean score 1.24) than males $(0.60, p<.001)$. When different twin pairs were analyzed separately, the males of the OS pairs were sadder (0.30) than the males of the SS pairs $(0.11, p=.017)$. No statistical differences in depression or other symptoms were found between females of different twin pairs.

\section{Consequences of Physical Dominance}

When all male twins or, respectively, female twins were analyzed together, physical dominance-submissiveness at the age of 22-30 years had no association with depressiveness, nervousness, or psychosomatic symptoms as reported by the twins themselves (Tables 2a, 2b). We next compared depression scores in relation to dominance-submissiveness separately in SS male twins, OS male twins, SS female twins and OS female twins. Physical dominance-submissiveness did not result in any significant differences in any of the symptoms in the males of the SS twin pairs or the females of the OS twin pairs. The OS twin pairs included no physically submissive males, and the intermediate males of these pairs were more nervous $(3.14, n=51)$ compared to the dominant males $(2.00, n=18$; Mann-Whitney U-test test $p=.031)$. The females of the SS twin pairs who reported being physically submissive $(1.11, n=9)$ or dominant $(0.89, n=19)$ had more problems with selfconfidence compared to the intermediate twins ( 0.59 , $n=100$; Kruskall-Wallis test $p=.020)$. The intermediate SS females expressed less anhedony $(0.92, n=96)$ compared to the dominant $(1.42, n=19)$ or submissive females (1.00, $n=9$; Kruskall-Wallis test $p=.048)$. They also had least psychosomatic symptoms $(1.08, n=100)$ compared to the dominant $(1.74, n=19)$ and submissive twins (1.89, $n=9$; Kruskall-Wallis test $p=.010$ ).

\section{Consequences of Psychological Dominance on Depression Among Males}

Male twins submissive in the psychological domain reported more depression than did either intermediate or dominant males (Table 2a). When different twin pairs were analyzed separately, there was no difference in depression or its subscores in relation to psychological dominance among males from SS twin pairs (Figure 1).

The submissive males from OS twin pairs reported more depression (12.17) than did intermediate ones (4.69, post hoc $p=.001)$ or dominant ones $(0.33$, post hoc $p=.001)$ (Figure 1 ). The submissive male twins as a whole had lower self-confidence than intermediate or dominant males (Table 2a). This tendency was found among males from OS twin pairs (dominant 0.00, $n=3$; intermediate $0.74, n=65$; submissive $1.83, n=6$; Kruskall-Wallis test $p=.041)$. The submissive males from OS twin pairs also reported more anhedony $(2.50, n=6)$ than did dominant (0.33, $\mathrm{n}=3$, post hoc $p=.019)$ or intermediate OS male twins $(1.17, n=64$, post hoc $p=.017)$. In an analysis of all male twins together, submissive males were more sad than others (Table 2a). This was evident in OS pairs, where

\section{Table 1}

The Proportions of Dominance-submissiveness Reported by the Twins at the Age of 22-30 Years

\begin{tabular}{|c|c|c|c|c|c|c|c|c|c|c|c|c|}
\hline & \multicolumn{12}{|c|}{ Quality of dominance } \\
\hline & \multicolumn{3}{|c|}{ Physical } & \multicolumn{3}{|c|}{ Psychological } & \multicolumn{3}{|c|}{ Verbal } & \multicolumn{3}{|c|}{ Total } \\
\hline & Male & Female & Both & Male & Female & Both & Male & Female & Both & Male & Female & Both \\
\hline & $\%$ & $\%$ & $\%$ & $\%$ & $\%$ & $\%$ & $\%$ & $\%$ & $\%$ & $\%$ & $\%$ & $\%$ \\
\hline Before school age $(n)$ & (198) & $(216)$ & (414) & (195) & (210) & (405) & (192) & $(211)$ & (403) & (189) & (205) & (394) \\
\hline Dominant & 28.3 & 27.8 & 28.0 & 12.8 & 24.8 & 19.0 & 14.6 & 34.6 & 25.1 & 11.6 & 28.8 & 20.6 \\
\hline Intermediate & 53.0 & 46.3 & 49.5 & 72.8 & 63.3 & 67.9 & 70.3 & 46.9 & 58.1 & 74.6 & 60.5 & 67.3 \\
\hline Submissive & 18.7 & 25.9 & 22.5 & 14.4 & 11.9 & 13.1 & 15.1 & 18.5 & 16.9 & 13.8 & 10.7 & 12.2 \\
\hline & & & $p=n s$ & & & $p=.009$ & & & $p<.001$ & & & $<.001$ \\
\hline School age (n) & $(197)$ & $(213)$ & (410) & (197) & (209) & (406) & (195) & (211) & $(406)$ & (190) & (204) & (394) \\
\hline Dominant & 31.0 & 26.3 & 28.5 & 19.3 & 30.1 & 24.9 & 19.5 & 36.5 & 28.3 & 16.8 & 28.4 & 22.8 \\
\hline Intermediate & 52.8 & 47.4 & 50.0 & 61.9 & 55.5 & 58.6 & 60.5 & 43.1 & 51.5 & 71.1 & 60.3 & 65.5 \\
\hline Submissive & 16.2 & 26.3 & 21.5 & 18.8 & 14.4 & 16.5 & 20.0 & 20.4 & 20.2 & 12.1 & 11.3 & 11.7 \\
\hline & & & $p=.045$ & & & $p=.035$ & & & $p<.001$ & & & $p=.023$ \\
\hline After school age (n) & $(192)$ & (215) & (407) & (191) & (211) & $(402)$ & (193) & (211) & (404) & $(182)$ & (207) & (389) \\
\hline Dominant & 17.7 & 11.2 & 14.3 & 10.5 & 13.3 & 11.9 & 17.1 & 18.5 & 17.8 & 14.8 & 12.6 & 13.6 \\
\hline Intermediate & 76.0 & 75.8 & 75.9 & 83.2 & 82.0 & 82.6 & 76.7 & 75.8 & 76.2 & 79.7 & 82.1 & 81.0 \\
\hline Submissive & 6.3 & 13.0 & 9.8 & 6.3 & 4.7 & 5.5 & 6.2 & 5.7 & 5.9 & 5.5 & 5.3 & 5.4 \\
\hline & & & $p=.020$ & & & $p=n s$ & & & $p=n s$ & & & $p=n s$ \\
\hline
\end{tabular}

Note: $p$-value indicates the significance between the gender distribution of dominance at the defined age 
Table 2a

Male Emotional and Psychosomatic Symptoms in Relation to Dominance-submissiveness at the Age of 22-30 Years

\begin{tabular}{|c|c|c|c|c|c|c|c|c|c|}
\hline \multirow[b]{2}{*}{ Symptoms } & \multicolumn{2}{|c|}{ Dominant } & \multicolumn{2}{|c|}{ Intermediate } & \multicolumn{3}{|c|}{ Submissive } & \multicolumn{2}{|c|}{ Total } \\
\hline & mean & $(n)$ & mean & $(n)$ & mean & $(n)$ & $p$-value & mean & $(n)$ \\
\hline \multicolumn{10}{|l|}{ Physical dominance } \\
\hline Depressiveness & 3.97 & (33) & 4.47 & $(146)$ & 4.17 & (12) & $n s$ & 4.36 & (191) \\
\hline Low self-confidence & .61 & (33) & .71 & (143) & .67 & (12) & $n s$ & .69 & (188) \\
\hline Anhedony & .94 & (31) & 1.14 & (142) & .92 & (12) & $n s$ & 1.09 & (185) \\
\hline Sadness & .23 & (30) & .18 & (133) & .00 & (11) & $n s$ & .18 & (174) \\
\hline Nervousness & 2.18 & (34) & 2.67 & (141) & 2.75 & (12) & $n s$ & 2.59 & (187) \\
\hline Psychosomatic symptoms & .68 & (34) & .60 & (144) & .50 & (12) & $n s$ & .61 & (190) \\
\hline \multicolumn{10}{|l|}{ Psychological dominance } \\
\hline Depressiveness & 3.40 & $(20)\langle * * *\rangle\rangle$ & 4.11 & $(158)<* * *\rangle$ & 9.25 & (12) & $<.001$ & 4.36 & (190) \\
\hline Low self-confidence & .40 & $(20)<*>>$ & .66 & $(155)<*>$ & 1.50 & (12) & .015 & .68 & (187) \\
\hline Anhedony & .89 & (19) & 1.09 & (153) & 1.75 & (12) & $n s$ & 1.11 & (184) \\
\hline Sadness & .05 & $(19)\langle * *\rangle$ & .16 & $(141)<* *$ & .64 & (11) & .001 & .18 & (171) \\
\hline Nervousness & 2.90 & (20) & 2.49 & (154) & 3.58 & (12) & $n s$ & 2.61 & (186) \\
\hline Psychosomatic symptoms & .20 & $(20)\langle * *>>$ & .59 & $(156)<*>$ & 1.25 & (12) & .003 & .59 & (188) \\
\hline \multicolumn{10}{|l|}{ Verbal dominance } \\
\hline Depressiveness & 4.21 & $(33)<*>>$ & 4.03 & $(147)<* *>$ & 7.67 & (12) & .012 & 4.29 & (192) \\
\hline Low self-confidence & .52 & (33) & .68 & (144) & .92 & (12) & $n s$ & .67 & (189) \\
\hline Anhedony & 1.16 & (31) & 1.01 & (144) & 1.73 & (11) & $n s$ & 1.08 & (186) \\
\hline Sadness & .10 & (31) & .20 & (133) & .30 & (10) & $n s$ & .18 & (174) \\
\hline Nervousness & 2.31 & (32) & 2.56 & (144) & 3.58 & (12) & $n s$ & 2.58 & (188) \\
\hline Psychosomatic symptoms & .55 & $\left.(33)<<^{* *}\right\rangle>$ & .53 & $\left.(146)<{ }^{* * *}\right\rangle$ & 1.50 & (12) & $<.001$ & .60 & (191) \\
\hline \multicolumn{10}{|l|}{ Total dominance } \\
\hline Depressiveness & 3.15 & (27) & 4.32 & (144) & 6.60 & (10) & $n s$ & 4.27 & (181) \\
\hline Low self-confidence & .41 & (27) & .72 & (141) & .90 & (10) & $n s$ & .68 & (178) \\
\hline Anhedony & .77 & (26) & 1.12 & (139) & 1.50 & (10) & $n s$ & 1.09 & (175) \\
\hline Sadness & .11 & (27) & .20 & (127) & .20 & (10) & $n s$ & .18 & (164) \\
\hline Nervousness & 2.22 & (27) & 2.64 & $(140)$ & 3.40 & (10) & $n s$ & 2.62 & (177) \\
\hline Psychosomatic symptoms & .56 & $(27)<{ }^{* *}>>$ & .53 & $(143)<* *>$ & 1.50 & (10) & .002 & .59 & (180) \\
\hline
\end{tabular}

Note : < > indicates the significance between the two groups beside each other. < > indicates the significance between the two groups apart from each other. Post Hoc Bonferoni significance levels ${ }^{*} p<.05,{ }^{* *} p<.01,{ }^{* * *} p<.001$.

submissive males reported more sadness $(1.00, n=6)$ than either intermediate $(0.24, n=58)$ or dominant OS male twins $(0.00, n=2 ; p=.003)$, and the difference remained significant in post hoc analysis between the submissive and intermediate males $(p=.003)$.

\section{Consequences of Psychological Dominance on Depression Among Females}

When all female twins were analyzed together, there was no difference in depression in relation to psychological dominance-submissiveness (Table $2 \mathrm{~b}$ ). However, the dominant females expressed more sadness than intermediate ones. There was no significant difference in depression or any other symptom in relation to psychological dominance-submissiveness among females from OS twin pairs (Figure 1). In the SS twin pairs, however, the submissive females reported more depression (7.71) than did intermediate (4.35) or dominant SS female twins $(5.75, p=.039)$, but the differences were not significant in post hoc analysis (Figure 1). Anhedony scores were highest among the submissive females of the SS twin pairs (dominant 1.38, $n=16$; intermediate 0.90, $n=99$; submissive $1.57, n=7 ; p=.049$ ), but the differences were not significant in post hoc analyses. The intermediate females of the SS twin pairs reported less sadness $(0.17, n=102)$ than did dominant ones $(0.56$, $n=16$, post hoc $p=.028)$, but the difference was not significant compared to the submissive ones $(0.43, n=7)$.

\section{Consequences of Psychological Dominance on Nervous Complaints}

When nervousness was analyzed, the dominant males of the SS twin pairs were more nervous (3.29) than the intermediate (2.29) or submissive ones (2.83, Kruskal-Wallis test $p=.047)$ (Figure 2). On the other hand, the submissive males (4.33) of the OS twin pairs had more nervous complaints compared to the dominant males ( 0.67 , post hoc $p=.049)$ (Figure2). The dominant females as a whole, were more nervous than the intermediate ones (Table $2 \mathrm{~b}$ ). This difference was significant in the females of the SS twin pairs (dominant 3.81, intermediate 2.31, post hoc $p=.015$ ) (Figure 2).

\section{Consequences of Psychological Dominance on Psychosomatic Symptoms}

The psychologically submissive males had significantly more psychosomatic symptoms than the dominant or intermediate males (Table 2a). This tendency was seen among the males of the OS twin pairs (dominant 0.00; intermediate 0.67 ; submissive $1.50 ; p=.046$ ), but the differences were no longer significant in post hoc analyses (Figure 3). The difference was not significant among the males of the SS pairs.

\section{Consequences of Verbal Dominance on Depression Among Males}

Verbally submissive males were more depressive than intermediate ones or dominant males (Table $2 \mathrm{a}$ ). The submissive 
Table 2b

Females: Emotional and Psychosomatic Symptoms in Relation to Dominance-submissiveness at the Age of 22-30 Years

\begin{tabular}{|c|c|c|c|c|c|c|c|c|c|}
\hline \multirow[b]{2}{*}{ Symptoms } & \multicolumn{2}{|c|}{ Dominant } & \multicolumn{2}{|c|}{ Intermediate } & \multicolumn{3}{|c|}{ Submissive } & \multicolumn{2}{|c|}{ Total } \\
\hline & mean & $(n)$ & mean & $(n)$ & mean & $(n)$ & $p$-value & mean & $(n)$ \\
\hline \multicolumn{10}{|l|}{ Physical dominance } \\
\hline Depressiveness & 5.92 & (24) & 4.56 & (162) & 5.26 & $(27)$ & $n s$ & 4.80 & (213) \\
\hline Low self-confidence & .88 & (24) & .68 & (162) & .88 & (26) & $n s$ & .73 & (212) \\
\hline Anhedony & 1.29 & (24) & 1.02 & (157) & 1.15 & (27) & $n s$ & 1.07 & (208) \\
\hline Sadness & .29 & (24) & .26 & (160) & .26 & (27) & $n s$ & .26 & (211) \\
\hline Nervousness & 3.46 & (24) & 2.47 & (160) & 2.81 & (26) & $n s$ & 2.62 & (210) \\
\hline Psychosomatic symptoms & 1.67 & (24) & 1.16 & (160) & 1.33 & (27) & $n s$ & 1.24 & (211) \\
\hline \multicolumn{10}{|l|}{ Psychological dominance } \\
\hline Depressiveness & 5.43 & (28) & 4.60 & (171) & 6.30 & $(10)$ & $n s$ & 4.79 & (209) \\
\hline Low self-confidence & .64 & (28) & .74 & (170) & .80 & (10) & $n s$ & .73 & (208) \\
\hline Anhedony & 1.36 & (28) & 1.01 & (166) & 1.30 & (10) & $n s$ & 1.07 & (204) \\
\hline Sadness & .56 & $(27)\langle *\rangle$ & .22 & (170) & .30 & (10) & .024 & .27 & (207) \\
\hline Nervousness & 3.64 & $(28)<*>$ & 2.48 & (168) & 2.50 & $(10)$ & .015 & 2.64 & (206) \\
\hline Psychosomatic symptoms & 1.32 & (28) & 1.20 & (169) & 1.40 & $(10)$ & $n s$ & 1.23 & (207) \\
\hline \multicolumn{10}{|l|}{ Verbal dominance } \\
\hline Depressiveness & 5.08 & (39) & 4.42 & $(159)<*>$ & 7.67 & (12) & .015 & 4.73 & (210) \\
\hline Low self-confidence & .74 & (39) & .71 & (158) & .83 & (12) & $n s$ & .72 & (209) \\
\hline Anhedony & 1.08 & (38) & .99 & $\left.(156)<<^{*}\right\rangle$ & 1.75 & (12) & .049 & 1.05 & (206) \\
\hline Sadness & .32 & (38) & .24 & (157) & .33 & (12) & $n s$ & .26 & (207) \\
\hline Nervousness & 3.08 & (38) & 2.42 & (156) & 3.58 & $(12)$ & .038 & 2.61 & (206) \\
\hline Psychosomatic symptoms & 1.33 & (39) & 1.17 & $(156)$ & 1.58 & $(12)$ & $n s$ & 1.23 & (207) \\
\hline \multicolumn{10}{|l|}{ Total dominance } \\
\hline Depressiveness & 5.35 & (26) & 4.46 & (169) & 7.18 & (11) & .053 & 4.71 & (206) \\
\hline Low self-confidence & .81 & (26) & .69 & (168) & 1.00 & (11) & $n s$ & .72 & (205) \\
\hline Anhedony & 1.23 & (26) & .98 & (165) & 1.64 & (11) & $n s$ & 1.05 & (202) \\
\hline Sadness & .48 & (25) & .23 & (168) & .30 & $(10)$ & $n s$ & .26 & (203) \\
\hline Nervousness & 3.50 & $(26)<*>$ & 2.42 & (165) & 3.45 & (11) & .013 & 2.62 & (202) \\
\hline Psychosomatic symptoms & 1.38 & (26) & 1.19 & (166) & 1.09 & (11) & $n s$ & 1.21 & (203) \\
\hline
\end{tabular}

Note : < > indicates the significance between the two groups beside each other. < > indicates the significance between the two groups apart from each other. Post Hoc Bonferoni significance levels ${ }^{*} p<.05,{ }^{* *} p<.01,{ }^{* * *} p<.001$.

males from SS twin pairs reported significantly more depression (7.43) than did intermediate male twins (3.58, post hoc $p=.015)$ (Figure 4$)$. They also reported lower selfconfidence $(1.29, n=7)$ than did dominant $(0.35$, $n=20$, post hoc $p=0.039)$ SS male twins, but the difference compared to the intermediate twins $(0.61, n=90)$ was not significant. In OS pairs, differences in depression (Figure 4) or its subscores among males in relation to verbal dominance-submissiveness did not reach statistical significance.

\section{Consequences of Verbal Dominance on Depression Among Females}

Verbally submissive females were more depressive than intermediate ones (Table 2b). In SS twin pairs, females submissive in the verbal domain reported most depression (dominant 5.67; intermediate 4.11; submissive 7.64; $p=.005)$, and the difference was significant in post hoc analysis between the submissive and intermediate females $(p=.010)$ (Figure 4$)$. The verbally submissive females as a whole reported more anhedony than the intermediate ones (Table 2b). This was seen in a comparison of the three groups in the SS pairs (dominant 1.19, $\mathrm{n}=26$; intermediate $0.85, n=86$; submissive $1.64, n=11 ; p=.016$ ), and the difference in post hoc analysis was significant between the submissive and intermediate females $(p=.028)$. In OS twin pairs only one female reported being verbally submissive to her male twin partner, and there was no difference in any of the symptoms in OS females in relation to dominance-submissiveness (Figures 4, 5 \& 6).

\section{Consequences of Verbal Dominance on Nervous Complaints}

Verbally submissive males of the OS twin pairs reported the most nervousness (dominant 1.54; intermediate 3.04; submissive $3.80 ; p=.049$ ) (Figure 5). The intermediate females of the SS pairs were least nervous (dominant 3.44; intermediate 2.14; submissive 3.55 ; $p=.002$ ), and the difference was significant in post hoc analysis between the intermediate and dominant females $(p=.007)$ (Figure 5).

\section{Consequences of Verbal Dominance on Psychosomatic Symptoms}

Verbally submissive males reported more psychosomatic symptoms than did intermediate males or those who were dominant (Table 2a). This was evident in the SS twin pairs (submissive, 1.43, compared to intermediate ones, 0.45 , post hoc $p=.004$ ) as well as in the OS pairs (submissive, 1.60 , compared to the dominant males, 0.38 , post hoc $p=.032$ ) (Figure 6). Among female twins there were no differences in psychosomatic symptoms in relation to verbal dominance-submissiveness (Table 2b, Figure 6).

\section{Consequences of Total Dominance Among Males}

When both genders were analyzed together, twins who were submissive, based on the total scores of dominance, were more depressive (6.90) than dominant (4.23, post hoc $p=.027)$ or intermediate twins (4.39, post hoc 

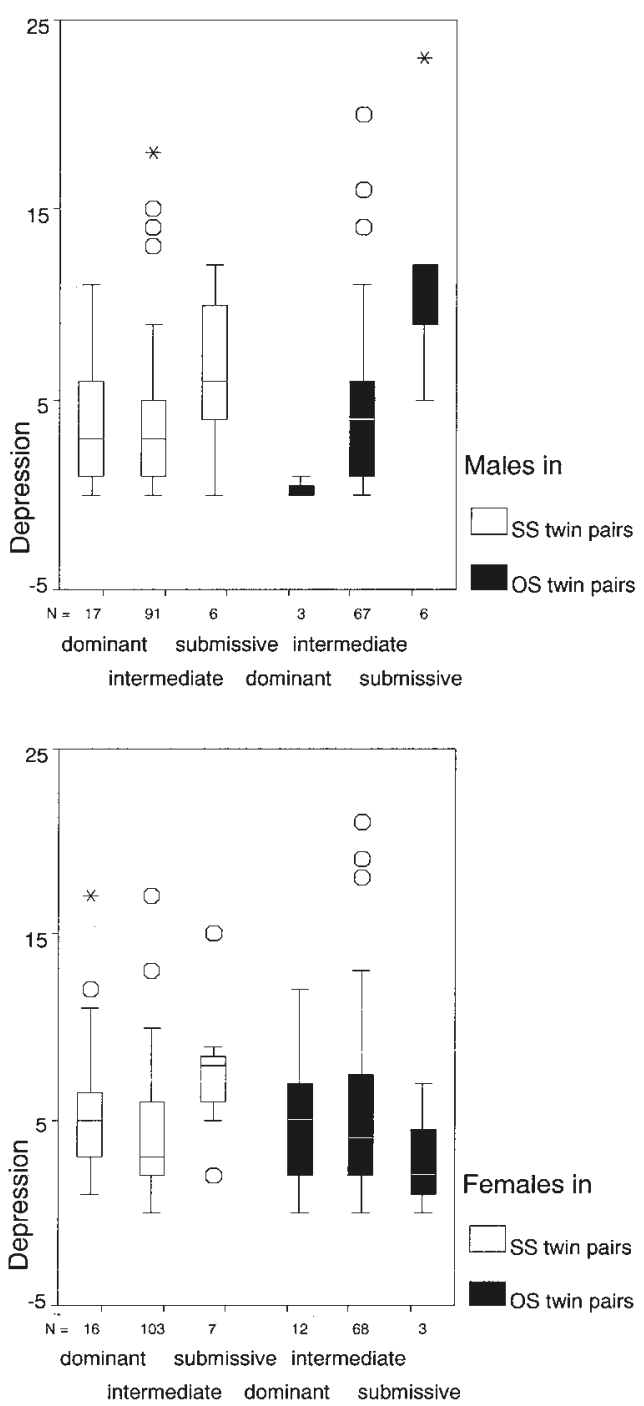

Figure 1

Psychological dominance and depression in twins of different kind of twin pairs. The line in the box-plot points the median, box-part is covering the inter-quartile range, and the whiskers include all but the outside observations $\left(0> \pm 2 S D\right.$ and ${ }^{*}> \pm 3 S D$ observations) (Tukey, 1977).

$p=.015)$. This difference didn't reach significance when all male twins were analyzed together (Table 2a). However, this was evident among the males from OS twin pairs (dominant 2.25, $n=12$; intermediate $5.30, n=54$; submissive 10.50 , $n=2 ; p=.036$ ), but the differences were not significant in post hoc analyses. Submissive males from OS pairs also reported more anhedony $(3.0, n=2)$ than did dominant $(0.58, n=12)$ or intermediate OS male twins $(1.24, n=51$, $p=.011)$, and in post hoc analysis the difference between submissive and dominant males was significant $(p=.012)$. Submissive OS male twins had a tendency to be more nervous $(6.00, n=2)$, than dominant $(2.00, n=12)$ or intermediate OS males $(2.92, n=52 ; p=.057)$. Submissive males had more psychosomatic symptoms than intermediate ones
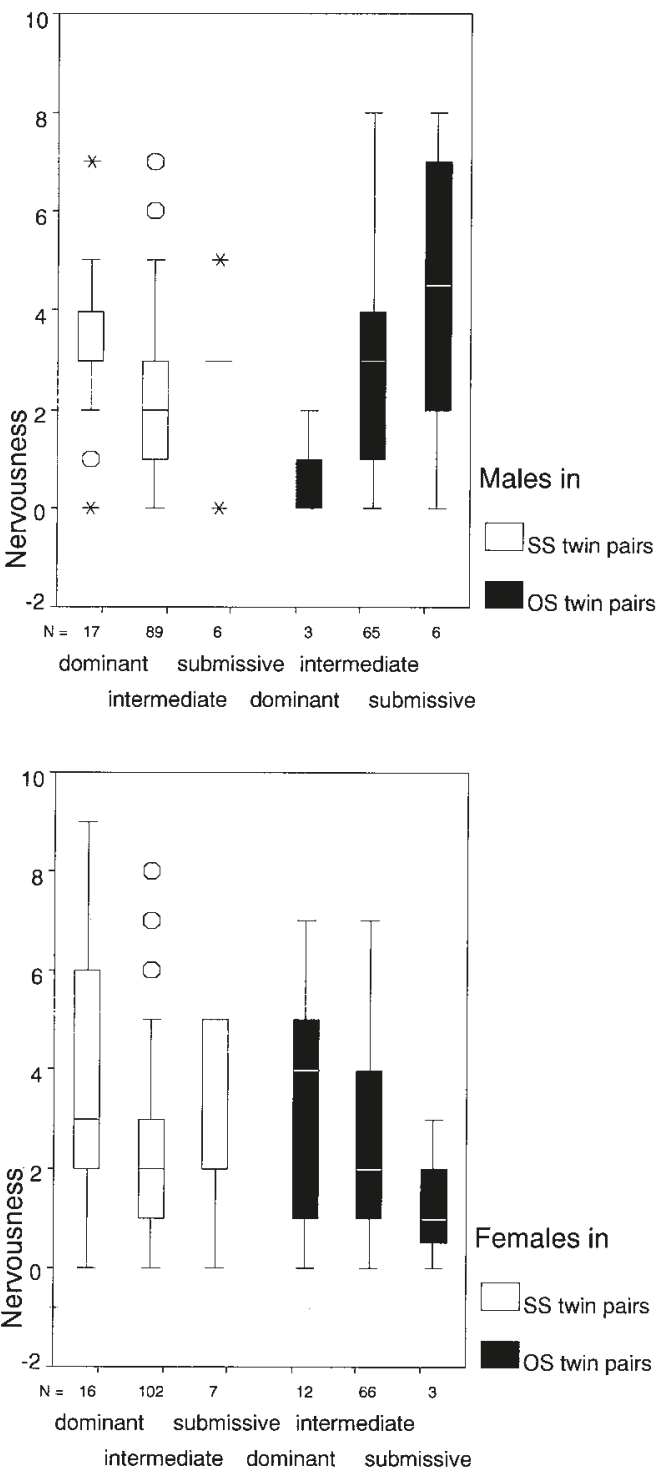

Figure 2

Psychological dominance and nervousness in twins of different kind of twin pairs.

or dominant ones (Table 2a). This was evident in OS male twins, and the submissive ones had more psychosomatic symptoms $(3.00, n=2)$ compared to both dominant $(0.67$, $n=12$, post hoc $p=.002)$ and intermediate OS males (0.64, $n=53$, post hoc $p=.001)$. In view of total dominance, there were no significant differences in any of the symptoms seen in the males of the SS twin pairs.

\section{Consequences of Total Dominance Among Females}

The tendency of submissive twins to report the most depressiveness did not reach statistical significance in female twins as a whole (Table 2b), nor in different female twin pairs. In OS twin pairs, intermediate females reported less sadness $(0.25, n=72)$ than dominant $(1.0, n=4)$ or submissive females $(0.67, n=3 ; p=.046)$. The intermediate female twins were less nervous than dominant ones 

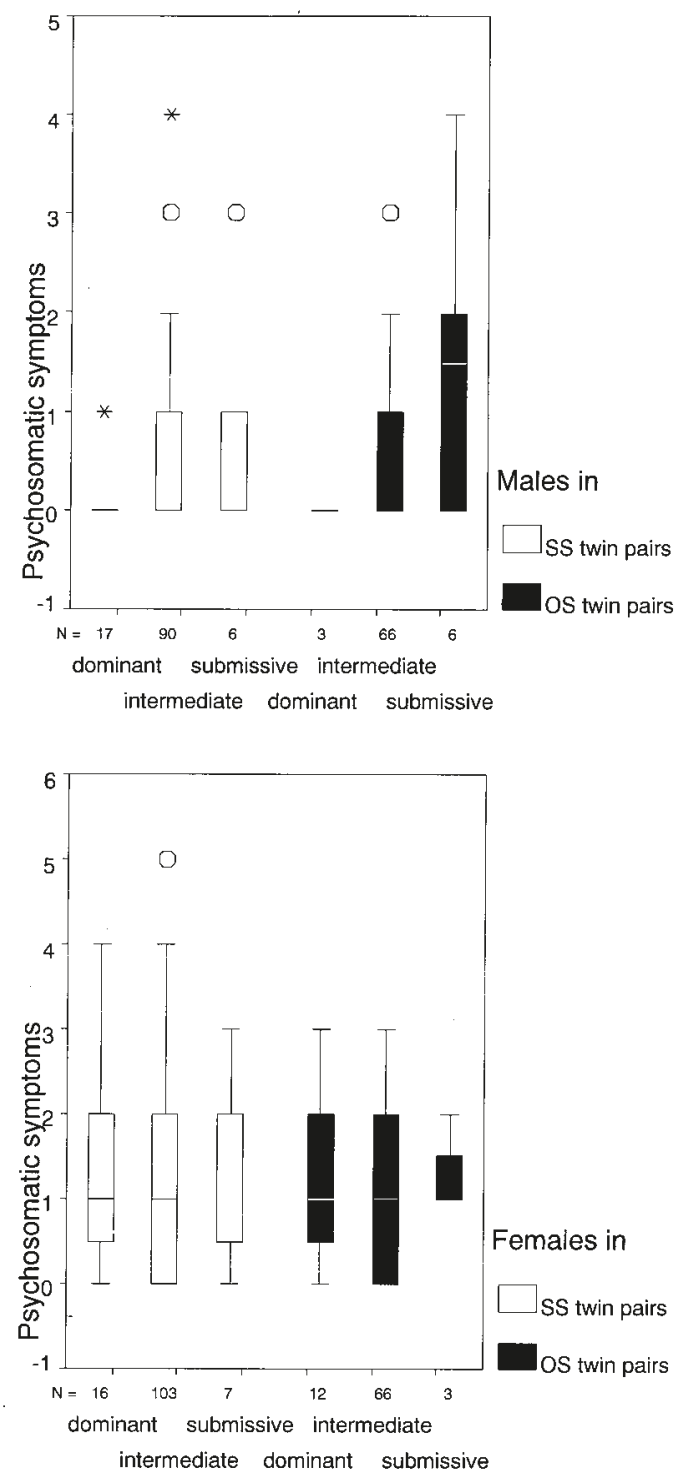

Figure 3

Psychological dominance and psychosomatic symptoms in twins of different kind of twin pairs.

(Table 2b), but this difference was not significant in the different twin groups.

\section{$\overline{\text { Discussion }}$}

This sample of twins permitted their follow up from pregnancy to young adulthood, to analyze changes in the inter-twin relationships with regard to dominance and submissiveness at different ages and developmental stages.

During adolescence, male twins reported dominance in the physical domain, while female twins more often reported dominance in the psychological domain (e.g., in deciding the twin pairs' "common opinions" and in assuming the role of a spokesperson for the twin pair) (Moilanen, 1987a). Females were psychologically and verbally dominant in early childhood already, while there was no
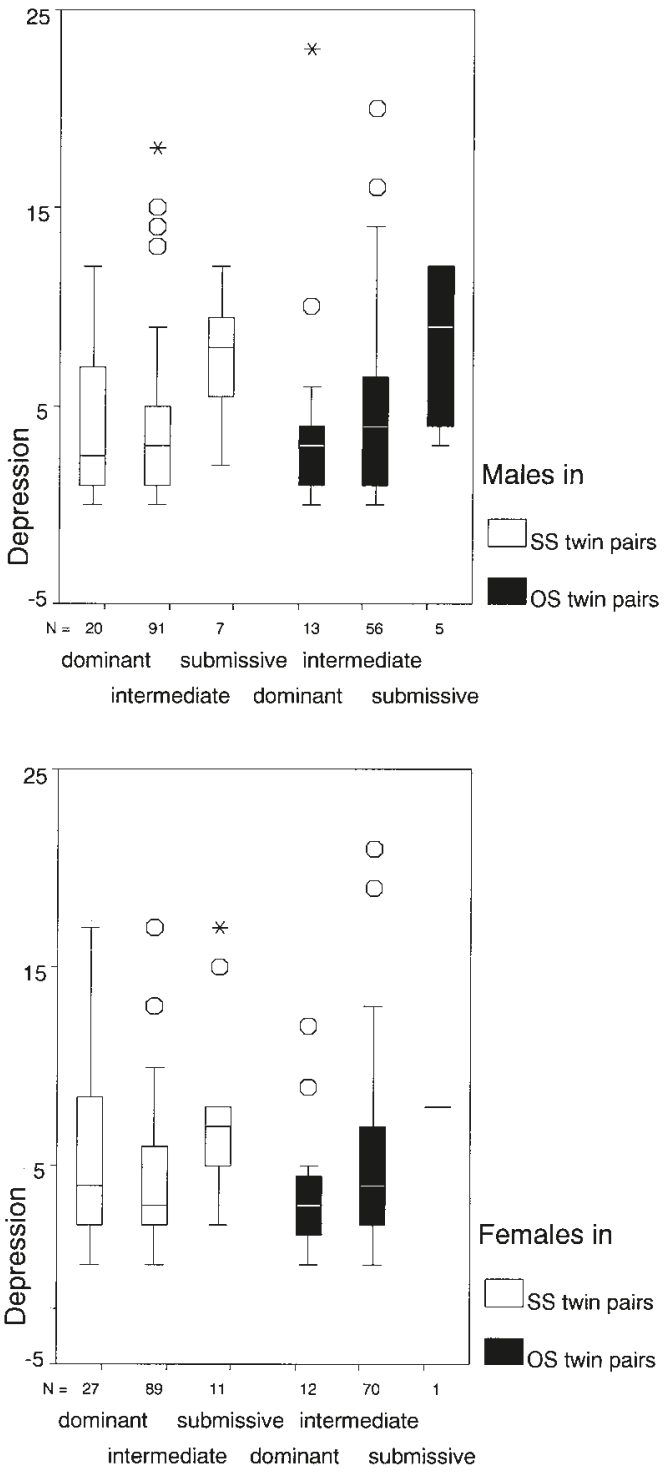

Figure 4

Verbal dominance and depression in twins of different kind of twin pairs.

significant difference in physical dominance before school age. In young adulthood, when the present analyses were made, males remained more often the physical leaders, while there was no difference in psychological leadership or in verbal dominance, manifested as a tendency to serve as a spokesperson for the twin pair. This partly contradicts the results reported by Ainslie (1985), who found in his qualitative study that, among male subjects, the differences in dominance were often manifested in terms of physical dominance during childhood, while with increasing age, the early physical dominance tended to be replaced by more delicate forms of interaction and actual domination to become less and less likely.

Our results also suggest that the relationship between co-twins changes and assumes different forms over time 

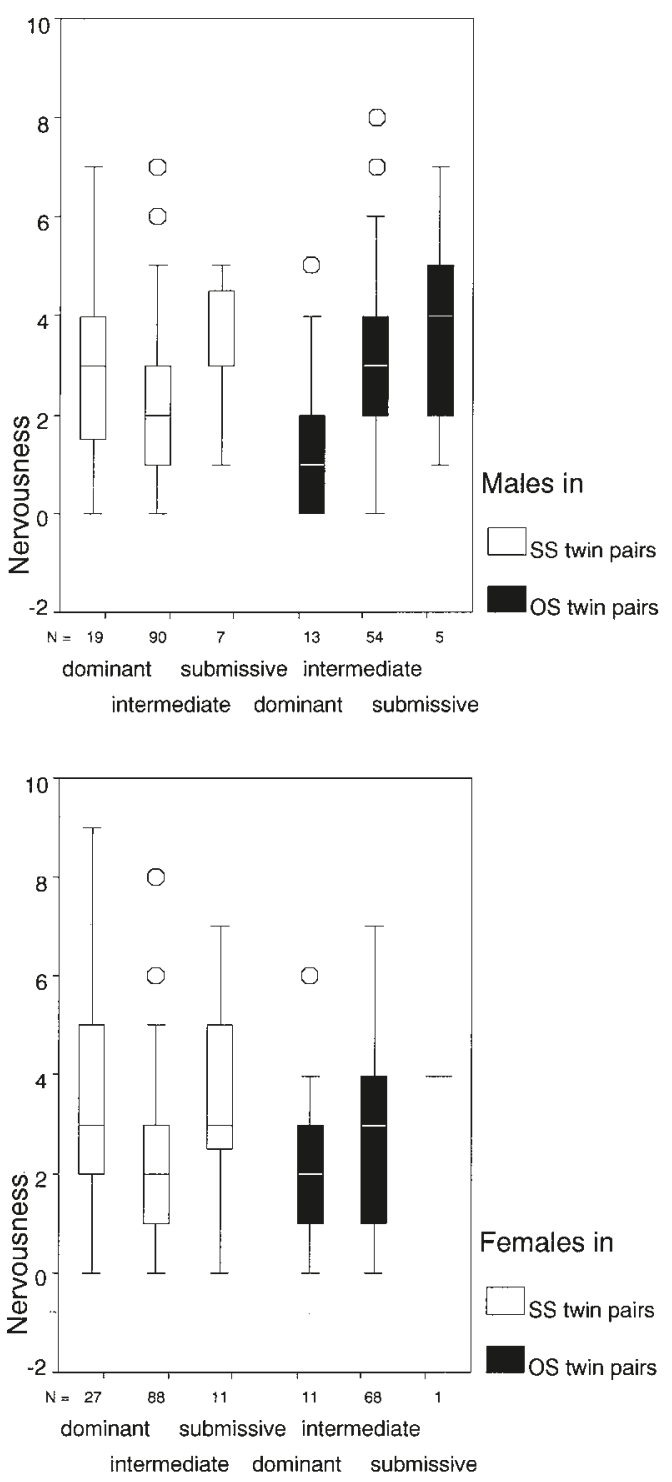

Figure 5

Verbal dominance and nervousness in twins of different kind of twin pairs.

and with increasing age. Dominant and submissive features in the twin relationship are likely to level off, and twins become more and more equal in their actions and behaviors. Young adulthood is an age when individuals increasingly assume responsibility for their own lives. Additionally, it is no longer possible to rely on the help of the co-twin, as young adults usually separate and live apart. In our sample, the tendency to be submissive or dominating decreased from school age to young adulthood, by which time over $80 \%$ of twins were in an intermediate position when the three domains of dominance-submissiveness were considered together.

In a previous follow-up of the same twins in adolescence, those who estimated themselves as being overall
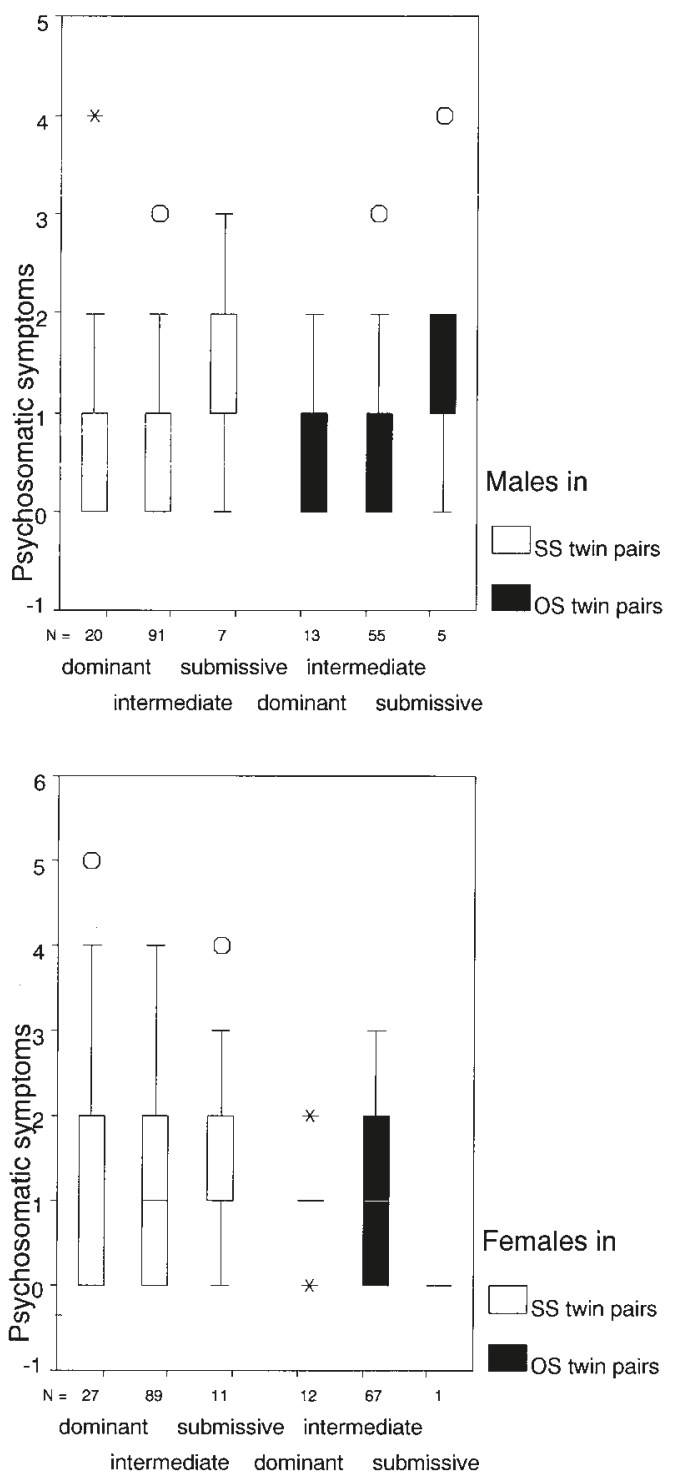

Figure 6

Verbal dominance and psychosomatic symptoms in twins of different kind of twin pairs.

submissive had more depressive and psychosomatic symptoms (Moilanen, 1987b). When different twin pairs were now analyzed separately in young adulthood, more detailed results were obtained about the connections between dominance-submissiveness and mental wellbeing. The small number of dominant and submissive twins in different submissiveness-dominance domains create some caution in making generalizations from our results.

The domain most important for subjective wellbeing in young adulthood seemed to be psychological dominancesubmissiveness. The males from OS twin pairs seemed to suffer most from submissiveness to a twin sister in the psychological domain. These males reported more often psychological problems such as depressiveness, sadness, 
anhedony, low self-confidence, as well as nervousness and psychosomatic symptoms. On the other hand, the psychologically submissive females of the SS twin pairs had more symptoms, including depression and anhedony. Intermediate position seemed to protect these females from most symptoms. For both male and female twins, it seems to be difficult to be "inferior" to their twin sister in young adulthood. In the early development of both genders, the mother is usually the primary caregiver and the child is most dependent on her. The father's role, although vitally important, is more neutral, and the father supports the child's individuation process (Tyson \& Tyson, 1990). Because of the closeness of the early relationship to the mother, a large variety of archaic feelings are easily directed towards the mother. Other females, especially ones wielding authority, such as a dominant female sister, may also evoke the early conflicting emotions that were an inevitable part of the early relationship.

Verbal submissiveness, on the other hand, did not create any difference in depressive symptoms among males in OS twin pairs. This may be due to the different roles shared by twins from same- and opposite-sex pairs. The female twin in an OS pair seems to be experienced "naturally" as the more talkative spokesperson, while the male twin is, just as naturally, the physically dominant one, and there is no real competition between the co-twins. Between males, verbal dominance seems to have different implications, and our results associate verbal submissiveness to a same-sex male co-twin to depression, lowered self-confidence, and psychosomatic symptoms. However, the verbally submissive males of the OS twin pairs seemed to be more nervous and to have psychosomatic symptoms, and not being physically dominant also increased nervous complaints. It may well be that verbally and physically submissive males are more timid, reserved, and anxious than males who express themselves more freely.

Between female co-twins, verbal dominance or submissiveness seemed to be a risk for depression and nervousness, and the submissive females expressed most anhedony. It may be that, while more "natural" for women to be more talkative and to assume the role of spokesperson, this role also involves some stress. On the other hand, intermediate position in the physical dominance of the females of the SS twin pairs seemed to protect from anhedony, problems of self confidence and psychosomatic symptoms, which may reflect the situation that these females didn't have a need to take an aggressively active role and possibly be in disharmony with the female role expectations, nor did they need to be passive.

Also, psychological dominance in both the males and females of the SS twin pairs was associated with nervousness. It may well be that an active role in a symmetric relationship requires more aggression and also generates nervous complaints. In adolescence, the twins who had been assessed by their parents to be more dominating verbally had suffered more commonly from nervous symptoms, but the number of depressive symptoms increased in submissive twins as well (Moilanen, 1991, 1996). Neurotic symptoms have also previously been associated with dominance among twins (Tienari, 1966), which is consistent with the elevated frequency of nervous symptoms in dominating twins, but contradictory to the finding that depressive symptoms are more frequent among submissive twins.

Total dominance was not so clearly associated with psychological symptoms as was psychological dominance. This may reflect the fact that most twins in young adulthood were in an intermediate position when the different aspects of dominance were taken into account. However, submissive males of OS twin pairs seemed to be in risk of being more depressed, and have anhedony, nervousness and psychosomatic symptoms. We must note that these results are based on only two submissive male OS twins.

Kendler et al. (1998) found female twins to have lower self esteem when they had grown up with a male co-twin than when the co-twin had been female. In our sample, we found no difference in symptoms between female twins from different twin pairs. Contrariwise, men from OS twin pairs were sadder than men growing with an SS twin pair. It seems also harder for a male to be submissive, and this is consistent with the expectations that males will be active and dominant, while it is more in accordance with the expectations applied to females to be more submissive. In our sample, position on the dimension of dominancedepressiveness of the females of the OS pairs did not cause many differences in subjective symptoms.

Why do submissive twins seem to suffer more even in adulthood? One explanation could be the frequently presented argument that, during adolescence, twins need to separate not only from their parents, but also from each other. They need to find ways to cope with the negative emotions aroused by competition, comparison, and the consistent pattern of the dominant co-twin getting his or her way more frequently. Still, submissive individuals should maintain, as far as possible, positive self- evaluations that will enhance their mental health, particularly in such areas as self-esteem, depression, and anxiety. Entrapment and defeat have also been associated with depression in singletons (Gilbert et al., 2002).

Although neurotic traits have been connected with hereditary factors in twin studies (Muhs \& Schepank, 1995), our results suggest that the quality of the twin relationship is also associated with different psychological symptoms. Genetic studies of behavior have previously been criticized for their failure to include measured environmental measures. Human relationships in twin families, co-twin dependence, dominance and submissiveness between twins have an impact on the twins' mental wellbeing and should therefore be included as developmental factors in genetic analyses of mental health.

In the future, to make genetic analysis possible, we are planning to analyze the same results on differences in dominance-submissiveness in relation to the twins' zygosity as well as their gender.

\section{References}

Ainslie, R. C. (1985). The psychology of twinship. Lincoln, NE: University of Nebraska Press.

Brody, G. H., Stoneman, Z., \& McCoy, J. K. (1994). Forecasting sibling relationships in early adolescence from child 
temperaments and family processes in middle childhood. Child Development, 65, 771-784.

Bruch, H. (1969). The insignificant difference: Discordant incidence of anorexia nervosa in monozygotic twins. American Journal of Psychiatry, 126, 85-90.

Gilbert, P., Allan, S., Brough, S., Melley, S., \& Miles, J. N. (2002). Relationship of anhedonia and anxiety to social rank, defeat and entrapment. Journal of Affective Disorders, 71, $141-151$.

Jouppila, P., Kauppila, A., Koivisto, M., Moilanen, I., \& Ylikorkala, O. (1975). Twin pregnancy. II. The role of active management during pregnancy and delivery. Acta Obstetricia et Gynaecologica Scandinavica, Supplement 44, 13-19.

Kauppila, A., Jouppila, P., Koivisto, M., Moilanen, I., \& Ylikorkala, O. (1975). Twin pregnancy. I. A clinical study of 335 cases. Acta Obstetricia et Gynaecologica Scandinavica, Supplement 44, 5-12.

Kendler, K. S., Gardner, C. O., \& Prescott, C. A. (1998). A population-based twin study of self-esteem and gender. Psychological Medicine, 28, 1403-1409.

Koivisto, M., Jouppila, P., Kauppila, A., Moilanen, I., \& Ylikorkala, O. (1975). Twin pregnancy. III. Neonatal morbidity and mortality. Acta Obstetricia et Gynaecologica Scandinavica, Supplement 44, 21-29.

Kovacs, M. (1980). Rating scales to assess depression in schoolaged children. Acta Paedopsychiatrica, 46, 305-315.

Kringlen, E. (1967). Heredity and environment in the functional psychoses. An epidemiological clinical twin study. Oslo: University Press.

Lytton, H. (1980). Parent-child interaction: The socialization process observed in twin and singleton families. New York: Plenum Press.

Moilanen, I. (1979). To be born as a twin - Risks and sequelae. Acta Universitatis Ouluensis, Series D Medica 50, (Thesis).

Moilanen, I. (1987a). Dominance and submissiveness between twins. I. Perinatal and developmental aspects. Acta Geneticae Medicae et Gemellologiae, 36, 249-255.

Moilanen, I. (1987b). Dominance and submissiveness between twins. II. Consequences for mental health. Acta Geneticae Medicae et Gemellologiae, 36, 257-265.

Moilanen, I. (1988a). Psychic vulnerability as a sequel to perinatal morbidity. A longitudinal twin study with special reference to psychiatric morbidity and inter-twin dependency. Acta Paediatrica Scandinavica, 77(Supplement 344), 95-105.
Moilanen, I. (1988b). Psychic vulnerability as a sequel to perinatal morbidity. A longitudinal twin study with special reference to neonatal mother-child separation. Lastenpsykiatrian tutkimussäätiön julkaisusarja, 2(1), 29-36.

Moilanen, I. (1990). Components of childhood depression. Reports of Psychiatrica Fennica, Report No 91, 85-91.

Moilanen, I. (1991). Psychosomatic symptoms in adolescent twins. Longitudinal twin study with special reference to psychosomatic symptoms. Psychotherapy \& Psychosomatics, $56,88-93$.

Moilanen, I. (1996). Twins in adolescence. Newsletter of Multiple Birth (London), 31, 1-4.

Moilanen, I., \& Pennanen, P. (1997). 'Mother's child' and 'father's child' among 14 twins. Acta Geneticae Medicae et Gemellologiae, 46, 219-230.

Moilanen, I., \& Ebeling, H. (1998). To be born as a twin — Risks and sequelae. Wellbeing and health. Background for Northern Finland 1966 birth cohort research. Journal of Circumpolar Health, 57, 138-147.

Muhs, A., \& Schepank, H. (1995). Influence of hereditary factors in psychogenic disorders. Psychopathology, 28, 177-184.

Rimpela, A., Rimpela, M., \& Honkala, E. (1983). Sairastavuus, kuolleisuus ja koettu terveys. In M. Rimpela (Ed.), Health habits among Finnish youth (Publications of the National Board of Health, Finland. Series Original Reports 4, pp. 191-207). Helsinki: National Board of Health.

Robin, M., Josse, J., \& Tourrette, C. (1988). Early mother-twin interaction. Acta Geneticae Medicae et Gemellologiae, 37, 151-159.

Rutter, M., \& Redshaw, J. (1991). Annotation: Growing up as a twin: Twin-singleton differences in psychological development. Journal of Child Psychology and Psychiatry, 32, 885-895.

Schave, B., \& Ciriello, J. (1983). Identity and intimacy in twins. New York: Praeger Publishers.

Tienari, P. (1963). Psychiatric illnesses in identical twins. Acta Psychiatrica Scandinavica, Supplement, 171.

Tienari, P. (1966). On intrapair differences in male twins with special reference to dominance-submissiveness. Acta Psychiatrica Scandinavica, Supplement, 188.

Tukey, J. (1977). Exploratory data analysis. Boston: AddisonWesley Inc.

Tyson, P., \& Tyson R. L. (1990). Psychoanalytic theories of development: An integration. London: Yale University Press.

Wing, J. K., Nixon, J. M., Mann, S. A., \& Leff, J. P. (1977). Reliability of the PSE (9th ed.) used in a population study. Psycholocigal Medicine 7, 505-516. 